\title{
Mechanical Behavior of Pericopsis elata Relative to Age during Growth
}

\author{
Foadieng Emmanuel $\mathbb{D}^{\mathrm{D}}{ }^{1,2,3}$ Fouotsa Woutsop Christian Martial, ${ }^{2,3}$ \\ Azeufack Tonfack Ulrich Gaël, ${ }^{2,3}$ Talla Pierre Kisito, ${ }^{3}$ and Fogue Medard ${ }^{2}$ \\ ${ }^{1}$ HTTTC Kumba, Department of Civil Engineering and Forestry Techniques, University of Buea, Buea, Cameroon \\ ${ }^{2}$ UR-ISIE, University of Dschang, Dschang, Cameroon \\ ${ }^{3} U R-2 M S P$, University of Dschang, Dschang, Cameroon
}

Correspondence should be addressed to Foadieng Emmanuel; foidienge@yahoo.fr

Received 3 July 2020; Revised 7 February 2021; Accepted 1 March 2021; Published 17 March 2021

Academic Editor: Antonio Gloria

Copyright (c) 2021 Foadieng Emmanuel et al. This is an open access article distributed under the Creative Commons Attribution License, which permits unrestricted use, distribution, and reproduction in any medium, provided the original work is properly cited.

\begin{abstract}
The assamela (afrormosia) whose scientific name is "Pericopsis elata" (Harms), a large tree of great commercial value, is an exploited species. It is considered "endangered" by the IUCN." Trees ready for harvesting are scarce because the logging diameter, which has been set at $100 \mathrm{~cm}$, is very big. The studies recommended by the Cameroonian government as part of the ITTO/CITES project activities should be carried out to determine a new minimum logging diameter as the diameter increases with age. No credible solution is provided in the scientific literature to compensate for its scarcity of exploitation. Moreover, little or no information is available for describing the variation of its mechanical properties over time in order to determine the age at which its wood mechanical properties are good enough to be marketable. It is in this context that this work was undertaken. In this study, we adopted an experimental approach to evaluate the mechanical properties of this species exploited in southeast Cameroon. We then studied the variations in these properties as a function of tree age in order to propose leads for their exploitation. Thus, the compression and bending tests allowed us to estimate the relationship between the mechanical properties in three main directions of the log (MOE in compression and bending, failure stress in compression and bending, and creep in compression) and age (or diameter). We also used the 10-hour creep under low axial compressive loading data to implement the theoretical fractional Maxwell (MF) model, which was compared to the experimental data. For this purpose, after three months of natural drying in the laboratory, we evaluated the above mechanical properties according to age. This study shows that the mechanical properties change as the diameter increases and change very quickly from $70 \mathrm{~cm}$ diameter upwards. From the analysis of the experimental data, we deduced that the minimum diameter of exploitable trees should be equal to $80 \mathrm{~cm}$ corresponding to the age of about 200 years.
\end{abstract}

\section{Introduction}

The forests of Central Africa are characterized by a significant specific wealth. Among the species they host, there are large sun-loving trees exploited for their wood, such as the assamela (afrormosia) whose scientific name is "Pericopsis elata" (Harms), a large tree of great commercial value. Pericopsis elata is a tree species of the Fabaceae family [1], commercially known as Afrormosia or Assamela. This exploited species is currently suffering from major regeneration problems in its natural area in the Congo Basin and, therefore, considered "endangered" by IUCN (International Union for the Conservation of Nature) [2].

In Cameroon, the Afrormosia reserves cover an area of about 4,071,857 ha and are mainly limited in the eastern region in the basins of the four rivers Dja, Boumba, Ngoko, and Sangha. Forest units (UFA) cover forty-two percent of this area.

For logging companies, the minimum exploitable diameter (MED) generally depends on the age of the tree. This diameter has been increased to $100 \mathrm{~cm}$ which is a serious problem for logging companies as they cannot find enough 
good quality resources. Trees of Pericopsis elata with a diameter of about $100 \mathrm{~cm}$ are rare and the few that exist have many heartwood defects. This is a major loss of income for the logging companies and the Cameroonian state, as Pericopsis elata wood is harvested almost dead and not alive. This minimum exploitable diameter needs to be redefined on a scientific basis.

To this purpose, on August 26 and September 13, 2013, the Government of Cameroon and OIBT (International Organization for Tropical Wood) signed an agreement on the implementation of two OIBT/CITES (Convention on International Trade in Endangered Species) program activities. Secondly, studies should be carried out to determine a new minimum diameter to be logged with an average growth diameter of $0.42 \pm 0.14 \mathrm{~cm}$ per year in natural mixed humid forest [3-5]. Botanical, physical, and mechanical properties have been determined [5]. No credible solution is provided in the scientific literature to reduce the scarcity of exploitation. Moreover, little or no information is available describing the variation of its mechanical properties over time in order to determine the age at which its wood mechanical properties are good enough to be marketable.

The objectives of our investigations are the evaluation of the mechanical properties of Pericopsis elata wood at different stages of growth and the study of the variations of these properties as a function of the age of the tree in order to propose leads for their exploitation. In this study, we adopted an experimental approach to evaluate the mechanical properties of this species logged in southeast Cameroon.

\section{Materials and Methods}

2.1. Description of the Species. Afrormosia or kokrodua, a large West African tree, is sometimes used as a substitute for teak (Tectona grandis). The heartwood is fine-textured, with a straight-to-interlaced grain. The wood is brownish yellow with darker streaks, moderately hard and heavy, weighing about $740 \mathrm{~kg} \times \mathrm{m}^{-3}$ at $12 \%$ moisture [5], and has a percentage of heartwood of about $88.7 \%$ [6]. The wood dries easily without degrading and has good dimensional stability.

Heartwood is highly resistant to fungal decay and termite attack and is extremely durable under adverse conditions. Pericopsis elata is often used for shipbuilding, joinery, flooring, furniture, interior trim, and decorative veneers [7].

2.2. Sample Collection. The different logs are cut into boards. Half of the boards come from live sawn and the other half from quarter sawn. This approach makes it possible to obtain the characteristics in the three main directions of orthotropy of wood (Figure 1). On this basis, 20 boards were selected and sent to the laboratory for the analysis phase.

2.3. Preparation of the Specimens. The machining method for the 4-point bending specimens met the requirements of NF B 51-008 [8] and NF B 51-016 [9] standards; compression (longitudinal, radial, and tangential) specimens complied

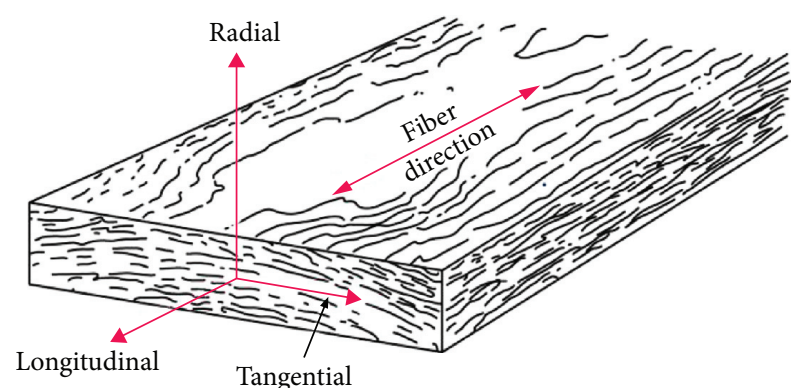

FIGURE 1: The main directions of orthotropy of wood material.

with ASTM D143-94 [10]. After almost three months of natural drying in the laboratory, the specimens were tested at a relative air humidity of $(65 \pm 5) \%$, for a relative temperature of $(23 \pm 2)^{\circ} \mathrm{C}$ for the entire duration of the tests. Apart from the fact that the specimens were not tested at the intended reference humidity (12\%), the general test conditions meet the requirements of French standard NF B 51003 [11].

\subsection{Test Specimen}

2.4.1. Test Specimen for Bending. The test specimen was $360 \mathrm{~mm}$ long, had a span length of $320 \mathrm{~mm}$, and a cross section of $20 \times 20 \mathrm{~mm}^{2}$ (Figure 2). To quantify the bending deflection, two strain gauges were bonded symmetrically to the specimen and parallel to its axis. They were cabled to form a Wheatstone half-bridge, as shown in Figure 2(b). Subsequently, twelve samples were selected for each series of tests.

After gluing the gauges, we checked the value of the resistances, reassuring the operation of the free contacts at the welding points. The gauges resistance after cabling, close to $(120.0 \pm 0.1) \Omega$, must be measured with a rather good accuracy, compared to typical values $(0.02 \%)$. The gluing of these gauges was carried out with Alteco 110 glue of Japanese manufacture. The deformations are measured directly by means of a modern EI 616 DELTALAB strain gauge bridge. The use of this bridge allows us to reduce the calculation, since it displays strains with an accuracy of $1 \mathrm{~mm} / \mathrm{mm}$.

2.4.2. Test Specimen for Compression. According to ASTM D143-94, the specimens are of straight prismatic shape, with a square cross section of $30 \mathrm{~mm}$ on each side and a length of $100 \mathrm{~mm}$ in the considered direction of orthotropy (Figure 3).

\subsection{Test Methods}

2.5.1. Test Descriptions. The qualification tests were carried out on the standardized specimens without defects.

Four-point-bending tests were conducted using a bending press $[12,13]$ according to the diagram in Figure 4. In order to remain within the elastic range, our specimens were subjected to stresses which were lower than one-third of the ultimate 4-point bending stress. In this case, our wood 


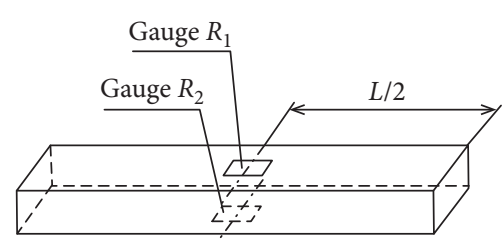

(a)

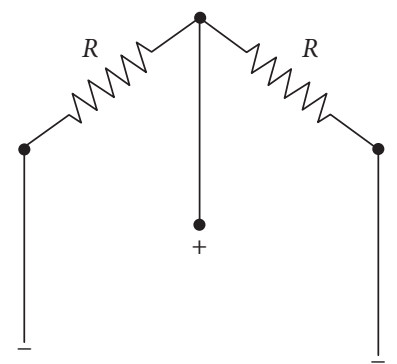

(b)

FIgure 2: (a) Position of the gauges; (b) Wheatstone half-bridge cabling diagram of the gauges.

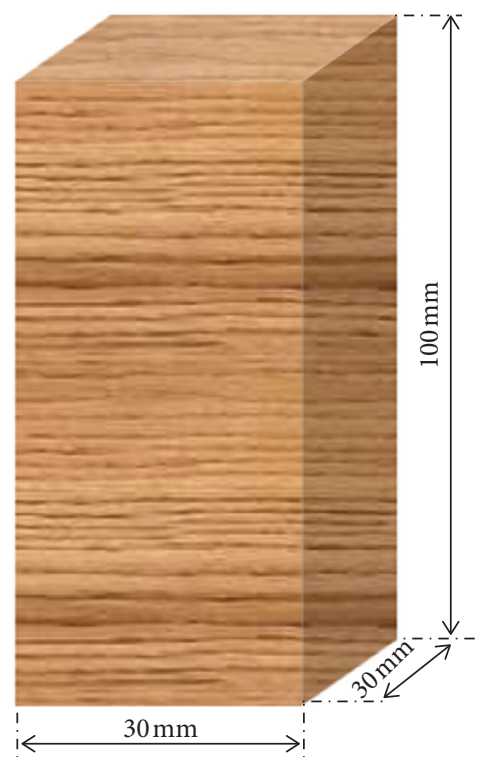

Figure 3: Standardized compression specimen [10].

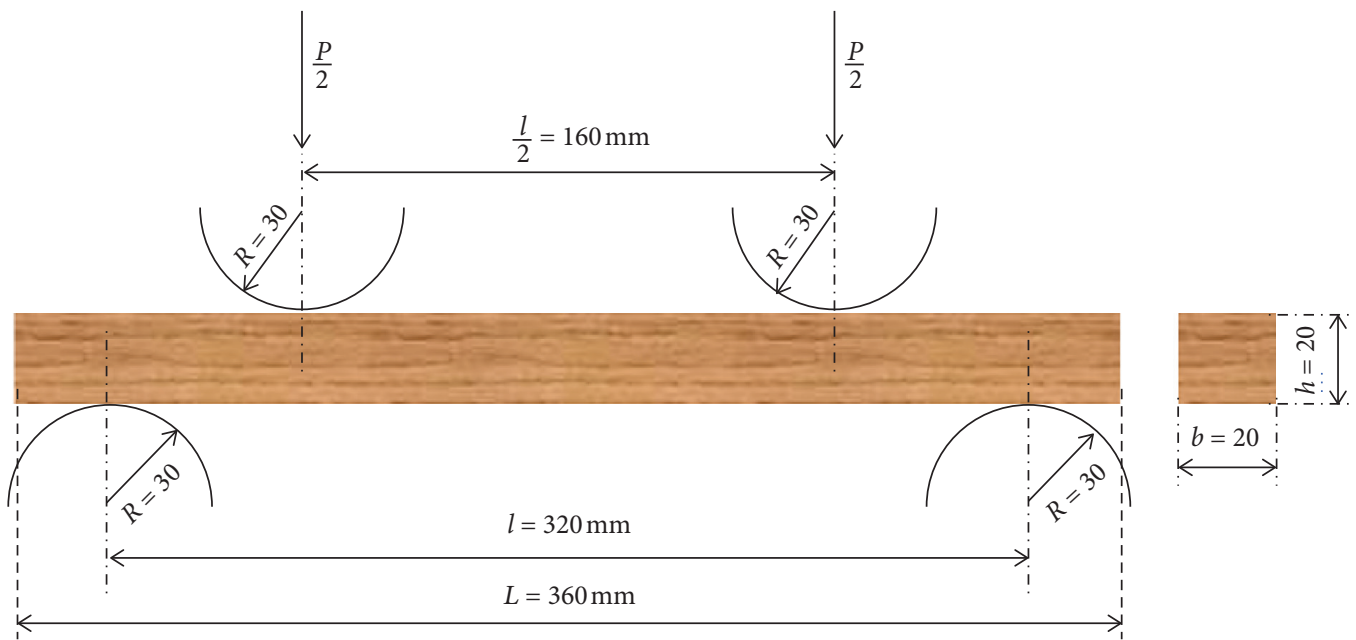

FIGURE 4: Standardized diagram of the experimental 4-point bending device [9]. 
material has an elastic behavior in accordance with Hooke's law.

The compression tests were carried out using a hydraulic press in the three orthotropic directions: axial, radial, and tangential. The specimens were also subjected to stresses in the elastic range as well as in bending.

2.5.2. Failure Stress and Modulus of Elasticity in Bending. The bending stress at failure is the maximum load that a material can momentarily endure before failure. The testing method, described by the French standard NF B 51-008 [8], allowed us to determine the 4-point bending strength of small, flawless specimens.

To determine the flexural modulus of elasticity, the adopted method consists of measuring the deformation in the zone of maximum stress of the specimens by means of resistive strain gauges as described in paragraph (2.4.1.). In order to remain within the elastic range, we have subjected our specimens to stresses less than or equal to one-third of the 4-point bending failure stress. In this case, the modulus of elasticity is calculated by linear stress $(\sigma) /$ strain $(\varepsilon)$ regression, where the flexural modulus of elasticity $(E)$ represents the slope of the straight line $\sigma=f(\varepsilon)$, with the square of the correlation coefficient greater than 0.99 according to NF EN 408 [14] standard. Hooke's law is thus applied:

$$
\sigma=E \cdot \varepsilon .
$$

2.5.3. Failure Stress in Axial Compression. The compressive failure stress in one of the three orthotropic directions expresses the resistance to compression of wood in the loaded direction. Depending on the sensitivity of our hydraulic press, we have opted to conduct our tests with the ASTM D143-94 standard [10].

2.5.4. Study of the Creep Behavior of Pericopsis elata. We used Riemann-Liouville derivative and the fractional Maxwell model to simulate the creep data of the specimen subjected to a low stress and its parameters. Being a biomaterial, wood presents a variability of mechanical properties, reason for which we opted for MF modelling before compared to the experimental data.

(1) Integral and Fractional Riemann-Liouville Derivative. For an arbitrary real or complex number $\alpha\left(\alpha \in \mathbb{R}_{+}^{*}\right)$, $\operatorname{Re}(\alpha)>0$, the Riemann-Liouville fractional integral (denoted by R-L) of order $\alpha$ of a function $f(t)$ is defined by

$$
I_{t}^{\alpha} f(t)=\frac{1}{\Gamma(\alpha)} \int_{0}^{t}(t-\tau)^{\alpha-1} f(\tau) \mathrm{d} \tau, \quad t>0, \alpha>0,
$$

where $\Gamma$ is the Gamma function:

$$
\Gamma(\alpha)=\int_{0}^{+\infty} t^{\alpha-1} e^{-t} \mathrm{~d} t
$$

The same definition can be used for the fractional derivative of order:

$$
\begin{array}{r}
D_{t}^{\alpha} f(t)=D^{n} I_{t}^{\alpha} f(t)=\frac{1}{\Gamma(n-\alpha)} \frac{\mathrm{d}^{n}}{\mathrm{~d} t^{n}} \int_{0}^{t}(t-\tau)^{n-\alpha-1} f(\tau) \mathrm{d} \tau, \\
t>0, \alpha>0, n-1 \leq \alpha<n,
\end{array}
$$

where $D^{n}=\mathrm{d}^{n} / \mathrm{d} t^{n}$

(2) Maxwell Fractional Rheological Model. The use of fractional derivatives for the mathematical modelling of viscoelastic materials is quite normal. For solids, the relationships between stress and strain are well known through the Hooke relation:

$$
\sigma(t)=E \cdot \varepsilon(t)
$$

Viscous friction is governed by Newton's relationship:

$$
\sigma(t)=\eta \cdot \dot{\varepsilon}(t)=\eta \frac{\mathrm{d} \varepsilon(t)}{\mathrm{d} t} .
$$

where $E$ and $\eta$ are, respectively, the modulus of elasticity of the spring and the viscosity of the viscous damper (Newton dashpot); $\sigma(t)$ and $\varepsilon(t)$ are stress and strain.

Relations (5) and (6) are not universal laws; they are only mathematical models for ideal solids and fluids, and they do not exist in reality. Noting that the stress is proportional to the zero-order derivative of strain for solids and to the firstorder derivative of strain for fluids, it is normal to assume that, for intermediate materials, the stress can be proportional to the intermediate-order derivative of strain [15].

Hooke's elastic element is symbolized by a spring, while Newton's viscous element is designated by a damper (Figure 5). It is practical in rheology to operate with such representations instead of the corresponding equations.

We call this constitutive relationship (see (7)) with the fractional derivative and the Scott Blair element, or Abel damper, as shown in Figure 5:

$$
\sigma(t)=\eta^{\alpha} \frac{\mathrm{d}^{\alpha} \varepsilon(t)}{\mathrm{d} t^{\alpha}}, \quad 0 \leq \alpha \leq 1
$$

where $\eta^{\alpha}$ is the coefficient of viscosity of the spring pot or Abel dashpot. When stress is a constant, $\sigma(t)=\sigma$, the Abel dashpot can describe a creep process. According to Riemann-Liouville theory, the relationship (7) can be transformed into (8) by fractional integral [16]:

$$
\varepsilon(t)=\frac{\sigma}{\eta^{\alpha}} \frac{t^{\alpha}}{\Gamma(1+\alpha)}, \quad 0 \leq \alpha \leq 1,
$$

where $\alpha$ can take different values, resulting in a set of creep curves described by the Abel damper.

By replacing in the classical Maxwell model the viscous damper by the spring-pot, we obtain a new fractional constitutive rheological model (Figure 6), called fractional Maxwell model (FMM)."

In Figure 6, the total deformation of the MF model is given by

$$
\varepsilon(t)=\varepsilon_{1}+\varepsilon_{2}(t)=\frac{\sigma}{E}+\frac{\sigma}{\eta^{\alpha}} \frac{t^{\alpha}}{\Gamma(1+\alpha)}, 0 \leq \alpha \leq 1,
$$




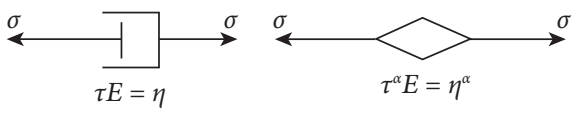

(a)

(b)

Figure 5: (a) Newton dashpot and (b) spring-pot or Abel dashpot.

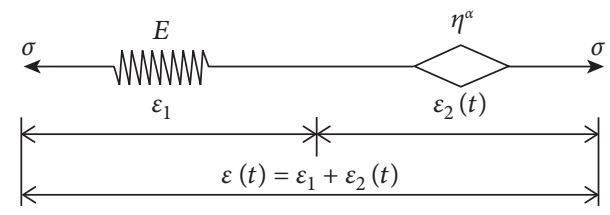

FIgURE 6: Fractional Maxwell rheological model (MF).

where $\varepsilon_{1}=\sigma / E$ and $\varepsilon_{2}(t)=\left(\sigma / \eta^{\alpha}\right)\left(t^{\alpha} / \Gamma(1+\alpha)\right)$ are, respectively, the deformations induced by the spring and the spring-pot during a creep test.

In the case of the strain $\varepsilon_{2}(t)$, the order of the fractional derivative can be considered to be a function of time; that is, $\alpha=n(t), \quad 0 \leq n(t) \leq 1$. The constitutive equation of the spring-pot is written as

$$
\sigma(t)=\eta^{n(t)} \frac{\mathrm{d}^{n(t)} \varepsilon_{2}(t)}{\mathrm{d} t^{\alpha}}, \quad 0 \leq n(t) \leq 1, t_{k-1} \leq t<t_{k}
$$

where $n(t)$ represents the order of the fractional derivative as a function of time and $\eta^{n(t)}$ the viscosity coefficient of the corresponding spring pot. When the stress is a constant, we obtain

$$
\varepsilon_{2}(t)=\sum_{k=1}^{p} \frac{\sigma}{\eta^{n_{k}}} \frac{\left(t-t_{k-1}\right)^{n_{k}}}{\Gamma\left(1+n_{k}\right)}, \quad 0 \leq n(t)=n_{k} \leq 1, t_{k-1} \leq t<t_{k},
$$

where $n_{k}$ represents the value of $n(t)$ at a specific instant of creep.

From the constitutive equation (9) of the MF model, the relation (12) is deduced:

$$
\begin{array}{r}
\varepsilon(t)=\varepsilon_{1}+\varepsilon_{2}(t)=\frac{\sigma}{E}+\sum_{k=1}^{p} \frac{\sigma}{\eta^{n_{k}}} \frac{\left(t-t_{k-1}\right)^{n_{k}}}{\Gamma\left(1+n_{k}\right)}, \\
0 \leq n(t)=n_{k} \leq 1, t_{k-1} \leq t<t_{k} .
\end{array}
$$

Equation (12) is that of the creep constitutive model, based on the theory of fractional calculus.

According to (12), the first creep phase has the constitutive equation:

$$
\begin{array}{r}
\mathcal{\varepsilon}(t)=\varepsilon_{1}+\varepsilon_{2}(t)=\frac{\sigma}{E}+\frac{\sigma}{\eta^{n_{1}}} \frac{t^{n_{1}}}{\Gamma\left(1+n_{1}\right)}, \\
0 \leq n_{1} \leq 1, t_{0}=0 \leq t<t_{1},
\end{array}
$$

where $\varepsilon_{1}=\varepsilon_{1}\left(t_{0}\right)=(\sigma / E)$ is the instantaneous elastic strain, from which we have the constant $E$ :

$$
E=\frac{\sigma}{\varepsilon_{1}\left(t_{0}\right)} \text {. }
$$

By introducing the decimal logarithm into the two members of (13), relations (15) and (16) are obtained:

$$
\log \left(\varepsilon(t)-\frac{\sigma}{E}\right)=\log \left(\frac{\sigma}{\eta^{n_{1}}} \frac{t^{n_{1}}}{\Gamma\left(1+n_{1}\right)}\right), \quad 0 \leq n_{1} \leq 1,0 \leq t<t_{1},
$$

$$
\begin{array}{r}
\log \left(\varepsilon(t)-\varepsilon\left(t_{0}\right)\right)=n_{1} \log (t)-\log \left(\frac{\eta^{n_{1}} \Gamma\left(1+n_{1}\right)}{\sigma}\right), \\
0 \leq n_{1} \leq 1,0 \leq t<t_{1} .
\end{array}
$$

By setting

$$
\left\{\begin{array}{l}
x=\log (t), \\
y=\log \left(\varepsilon(t)-\varepsilon\left(t_{0}\right)\right)
\end{array}\right.
$$

(16) is a straight line of the form

$$
y=a_{1} x+b_{1} .
$$

By graphically exploiting the experimental creep data (Figure 7) in the interval $0 \leq t<t_{1}$, we can determine the constants $a_{1}$ and $b_{1}$ of (18):

$$
\left\{\begin{array} { l } 
{ a _ { 1 } = n _ { 1 } } \\
{ b _ { 1 } = - \operatorname { l o g } ( \frac { \eta ^ { n _ { 1 } } \Gamma ( 1 + n _ { 1 } ) } { \sigma } ) }
\end{array} \Rightarrow \left\{\begin{array}{l}
n_{1}=a_{1} \\
\eta^{n_{1}}=\frac{\sigma}{\Gamma\left(1+n_{1}\right)} 10^{-b_{1}}
\end{array}\right.\right.
$$

By the same process in the interval $t_{1} \leq t \leq t_{2}$, relation (12) allows to express the constitutive equation in the second phase of creep:

$$
\begin{array}{r}
\varepsilon(t)=\frac{\sigma}{E}+\frac{\sigma}{\eta^{n_{1}}} \frac{t_{1}^{n_{1}}}{\Gamma\left(1+n_{1}\right)}+\frac{\sigma}{\eta^{n_{2}}} \frac{\left(t-t_{1}\right)^{n_{2}}}{\Gamma\left(1+n_{2}\right)}, \\
0 \leq n_{2} \leq 1, t_{1} \leq t<t_{2} .
\end{array}
$$

By introducing the decimal logarithm into the two members of (see (20)), one obtains

$$
\begin{array}{r}
\log \left(\varepsilon(t)-\varepsilon\left(t_{1}\right)\right)=n_{2} \log \left(t-t_{1}\right)-\log \left(\frac{\eta^{n_{2}} \Gamma\left(1+n_{2}\right)}{\sigma}\right), \\
0 \leq n_{2} \leq 1, t_{1} \leq t<t_{2},
\end{array}
$$

where $\varepsilon\left(t_{1}\right)=(\sigma / E)+\left(\sigma / \eta^{n_{1}}\right)\left(t_{1}^{n_{1}} / \Gamma\left(1+n_{1}\right)\right)$.

By considering

$$
\left\{\begin{array}{l}
x=\log \left(t-t_{1}\right), \\
y=\log \left(\varepsilon(t)-\varepsilon\left(t_{1}\right)\right),
\end{array}\right.
$$




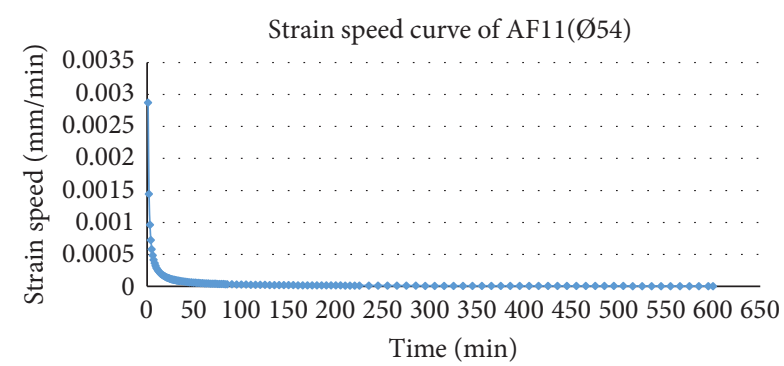

FIGURE 7: Deformation speed curve of AF11(Ø54) under a load of $\sigma=16.1865 \mathrm{MPa}$.

(21) is a straight line of the form

$$
y=a_{2} x+b_{2}
$$

Experimental creep data in the interval $t_{1} \leq t<t_{2}$ (Figure 8) allows us to determine the constants $a_{2}$ and $b_{2}$ of (23):

$$
\left\{\begin{array}{l}
n_{2}=a_{2}, \\
\eta^{n_{2}}=\frac{\sigma}{\Gamma\left(1+n_{2}\right)} 10^{-b_{2}} .
\end{array}\right.
$$

\section{Results and Discussion}

3.1. Failure Stress in Bending. Tables 1 and 2 summarize the failure stresses in 4-point bending for each diameter range. The hygroscopy of the wood material requires for a correct interpretation of the different results, to always indicate the humidity during the test. For this reason, in both tables, the failure stress $\left(\sigma_{u H}\right)$ of each specimen is accompanied by its moisture content $(H)$ during the test and the failure stress $\left(\sigma_{u 12}\right)$ at $12 \%$ moisture content.

The curve in Figure 9, which accompanies these two tables, shows that the average failure stress is an increasing function of the different diameter ranges. This curve increases very quickly from the $70 \mathrm{~cm}$ diameter. Starting at $78 \mathrm{~cm}$ diameter, we note that our results are significantly better than those in the literature from 93 to $103 \mathrm{MPa}$ $[17,18]$.

3.2. Modulus of Elasticity. Table 3 summarizes the different MOE (modulus of elasticity) in 4-point bending by diameter range.

Figure 10 shows sample linear regression curves (stress/ strain) used for the calculation of the MOE.

The curve in Figure 11 shows the evolution of the MOE as a function of the different diameter. We can see here that the MOE increases very quickly from diameter $70 \mathrm{~cm}$. This is more justified by the results of the study of the physical properties per diameter [6].

Looking at the results in Table 3, we see that, at $85 \mathrm{~cm}$ diameter, for an average moisture content of $11.98 \%$ during the test, the average value of the MOE found at $12 \%$ moisture is $10,511.59 \mathrm{MPa}$. Since this result is not very far from one of the results in the literature, which is $10,600 \mathrm{MPa}$ at $12 \%$ humidity [17], this result may be another strong argument

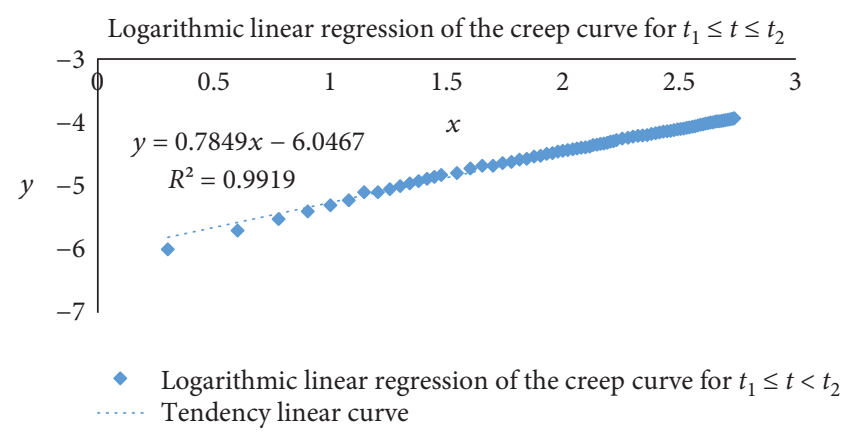

FIGURE 8: Logarithmic linear regression curve of creep in the interval $t_{1} \leq t \leq t_{2}$.

that could lead decision-makers to revise the logging diameter downwards.

\subsection{Compressive Failure Stress}

3.3.1. Axial Compressive Failure Stress. Tables 4 and 5 show the axial compressive failure stresses for the four diameter classes under consideration. It is noted here that the stress increases with diameter, which can be justified by the results obtained at the end of the physical characterization of Pericopsis elata by diameter [6].

Figure 12, which accompanies these tables, shows the shape of the variation of the average failure stresses per diameter. We note here that the axial failure stress increases with the diameter and very quickly from $70 \mathrm{~cm}$.

The axial tensile stress for diameters $54,70,78$, and $85 \mathrm{~cm}$, at $12 \%$ humidity, being, respectively, 66.81, 67.76, 70.15 , and $81.67 \mathrm{MPa}$. A comparison with the literature $(64 \mathrm{MPa})[17,18]$ reinforces the interest of this characterization by diameter.

3.3.2. Radial Compressive Failure Stress. Looking at the results in Tables 6 and 7, it can also be seen that the radial failure stress also increases with diameter. The average values by diameter, of the various radial failure stresses are much lower than those of the axial stresses. In his work, Guitard (1987) [19] had already noted the significant difference between fracture stresses in the two orthotropic directions.

Here, we notice a clear difference between the shapes of the curves in this radial direction (Figure 13) and those of the axial direction. Between the diameters $70 \mathrm{~cm}$ and $80 \mathrm{~cm}$, the curve grows slower than in the axial direction.

3.3.3. Tangential Compressive Failure Stress. As in the previous two directions, the results in the tangential direction (Tables 8 and 9) also reveal that the failure stress increases with the diameter.

In analyzing the results in the three orthotropic directions, it can be seen that the order of magnitude of the failure stresses corroborates that established by Guitard (1987) [19]. 
TABLE 1: Failure stresses in 4-point bending, diameters $54 \mathrm{~cm}$ and $70 \mathrm{~cm}$.

\begin{tabular}{|c|c|c|c|c|c|c|}
\hline \multirow{2}{*}{ Specimen } & \multicolumn{3}{|c|}{$\mathrm{AF}(\varnothing 54)$} & \multicolumn{3}{|c|}{$\mathrm{AF}(\varnothing 70)$} \\
\hline & $\sigma_{u H}(\mathrm{MPa})$ & $\sigma_{u 12}(\mathrm{MPa})$ & $H(\%)$ & $\sigma_{u H}(\mathrm{MPa})$ & $\sigma_{u 12}(\mathrm{MPa})$ & $H(\%)$ \\
\hline 1 & 81.25 & 80.29 & 11.70 & 88.38 & 89.40 & 12.29 \\
\hline 2 & 71.27 & 68.14 & 10.90 & 85.53 & 80.88 & 10.64 \\
\hline 3 & 78.40 & 74.15 & 10.64 & 92.66 & 91.20 & 11.61 \\
\hline 4 & 71.27 & 71.49 & 12.08 & 99.78 & 96.47 & 11.17 \\
\hline 5 & 71.27 & 67.37 & 10.63 & 99.78 & 102.60 & 12.71 \\
\hline 6 & 85.53 & 91.80 & 13.83 & 92.66 & 88.60 & 10.91 \\
\hline 7 & 88.38 & 79.65 & 11.61 & 92.66 & 88.96 & 11.00 \\
\hline 8 & 85.53 & 77.96 & 10.58 & 92.66 & 89.86 & 11.24 \\
\hline 9 & 69.85 & 76.05 & 10.74 & 85.53 & 50.96 & 12.41 \\
\hline 10 & 78.40 & 90.86 & 11.92 & 92.66 & 91.44 & 11.67 \\
\hline 11 & 82.68 & 85.63 & 11.86 & 89.81 & 97.29 & 11.61 \\
\hline 12 & 65.57 & 66.73 & 11.40 & 98.36 & 84.68 & 11.80 \\
\hline Average & 77.45 & 77.51 & 11.49 & 92.54 & 87.70 & 11.59 \\
\hline Standard deviation & 7.43 & 8.62 & 0.92 & 4.88 & 12.91 & 0.64 \\
\hline
\end{tabular}

Table 2: Failure stresses in 4-point bending, diameters $78 \mathrm{~cm}$ and $85 \mathrm{~cm}$.

\begin{tabular}{|c|c|c|c|c|c|c|}
\hline \multirow{2}{*}{ Specimen } & \multicolumn{3}{|c|}{$\mathrm{AF}(\varnothing 78)$} & \multicolumn{3}{|c|}{$\mathrm{AF}(\varnothing 85)$} \\
\hline & $\sigma_{u H}(\mathrm{MPa})$ & $\sigma_{u 12}(\mathrm{MPa})$ & $H(\%)$ & $\sigma_{u H}(\mathrm{MPa})$ & $\sigma_{u 12}(\mathrm{MPa})$ & $H(\%)$ \\
\hline 1 & 106.91 & 108.62 & 12.40 & 128.29 & 123.24 & 11.01 \\
\hline 2 & 114.04 & 119.36 & 13.17 & 121.17 & 117.51 & 11.25 \\
\hline 3 & 106.91 & 104.37 & 11.41 & 121.17 & 126.41 & 13.08 \\
\hline 4 & 111.19 & 107.24 & 11.11 & 136.85 & 138.81 & 12.36 \\
\hline 5 & 114.04 & 110.31 & 11.18 & 128.29 & 128.07 & 11.96 \\
\hline 6 & 99.78 & 97.18 & 11.35 & 121.17 & 117.15 & 11.17 \\
\hline 7 & 99.78 & 103.69 & 12.98 & 128.29 & 135.70 & 13.44 \\
\hline 8 & 114.04 & 116.36 & 12.51 & 121.17 & 114.61 & 10.65 \\
\hline 9 & 99.78 & 99.76 & 11.99 & 145.40 & 142.21 & 11.45 \\
\hline 10 & 99.78 & 96.47 & 11.17 & 135.42 & 132.34 & 11.43 \\
\hline 11 & 112.61 & 112.51 & 11.98 & 128.29 & 132.67 & 12.85 \\
\hline 12 & 114.04 & 112.70 & 11.71 & 118.32 & 123.49 & 13.09 \\
\hline Average & 107.74 & 107.38 & 11.91 & 127.82 & 127.68 & 11.98 \\
\hline Standard deviation & 6.39 & 7.34 & 0.72 & 8.07 & 8.89 & 0.95 \\
\hline
\end{tabular}

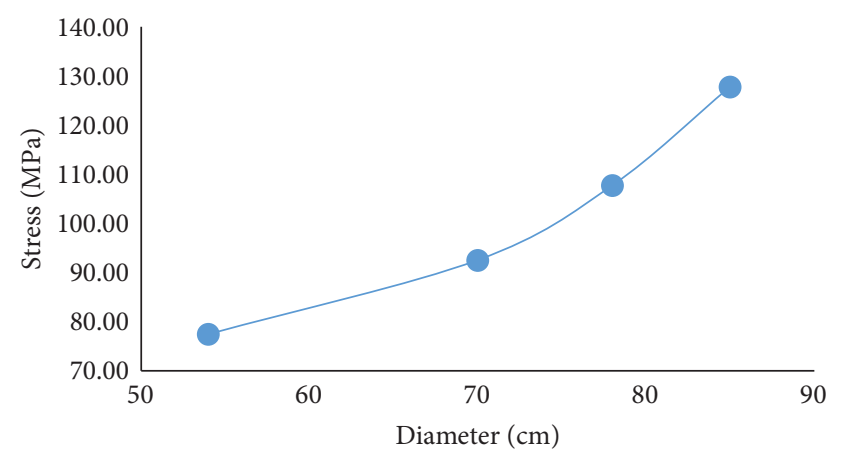

FIGURE 9: Variation curve of failure stress in 4-point bending per diameter range.

Figure 14 shows the variation in failure stresses in the tangential direction as a function of diameter. Here, a similarity between the radial (Figure 13) and tangential (Figure 14) directions can be seen.
As in the case of bending, we note that in compression, the literature underestimates the value of the breaking stress of Pericopsis elata. This factor is related to the variation in diameter not being taken into account during the various characterizations. An overall analysis of these results in the three orthotropy directions reveals that the order of magnitude of the failure stresses corroborates that established by the literature, illustrating the degree of anisotropy of the wood material. Nevertheless, it would be interesting to verify the consistency of these mechanical results in other regions in Cameroon.

\subsection{Creep Behavior}

3.4.1. Networks of Ten-Hour Creep Test Curves. Figures 15 and 16 show the networks of curves for 10 hours of creep for specimens $\varnothing 54$ and $\varnothing 70$ under a load of $16.1865 \mathrm{MPa}$.

An analysis of these two networks of curves shows that although the specimens in the same network are 
TABLe 3: Modulus of elasticity per diameter range.

\begin{tabular}{|c|c|c|c|c|}
\hline Specimen & $\begin{array}{c}\varnothing 54 \mathrm{~cm} \\
\text { MOE (MPa) }\end{array}$ & $\begin{array}{c}\varnothing 70 \mathrm{~cm} \\
\operatorname{MOE}(\mathrm{MPa})\end{array}$ & $\begin{array}{c}\varnothing 78 \mathrm{~cm} \\
\text { MOE (MPa) }\end{array}$ & $\begin{array}{c}\varnothing 85 \mathrm{~cm} \\
\operatorname{MOE}(\mathrm{MPa})\end{array}$ \\
\hline 1 & 7122.7 & 8120.4 & 9595.4 & 10087 \\
\hline 2 & 6608 & 8489.1 & 8963.7 & 10970 \\
\hline 3 & 6809.3 & 7969.2 & 8534.1 & 10244 \\
\hline 4 & 6957.2 & 7219.5 & 8524.4 & 11033 \\
\hline 5 & 5824 & 8029.6 & 8709.2 & 10187 \\
\hline 6 & 7131.4 & 8231.5 & 9685.8 & 11046 \\
\hline 7 & 7137.2 & 8532.9 & 9036.9 & 10210 \\
\hline 8 & 6707.4 & 8059.6 & 8617.5 & 10303 \\
\hline 9 & 6905.4 & 7306.7 & 8617.3 & 10581 \\
\hline 10 & 7017.4 & 8136.5 & 8802.8 & 10380 \\
\hline 11 & 5973.3 & 8306.5 & 8912.1 & 10693 \\
\hline 12 & 7147.4 & 8231.8 & 9805.7 & 10443 \\
\hline Average & 6778.39 & 8052.78 & 8983.74 & 10514.75 \\
\hline Standard deviation & 447.96 & 406.69 & 461.29 & 346.27 \\
\hline
\end{tabular}

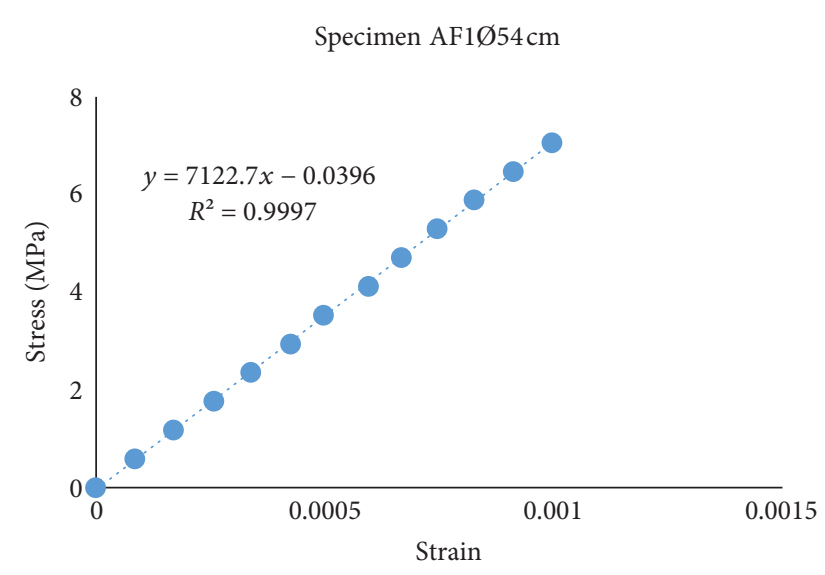

$\sigma=E \varepsilon=f(\varepsilon), \varnothing 54 \mathrm{~cm}$

Tendency linear curve

(a)

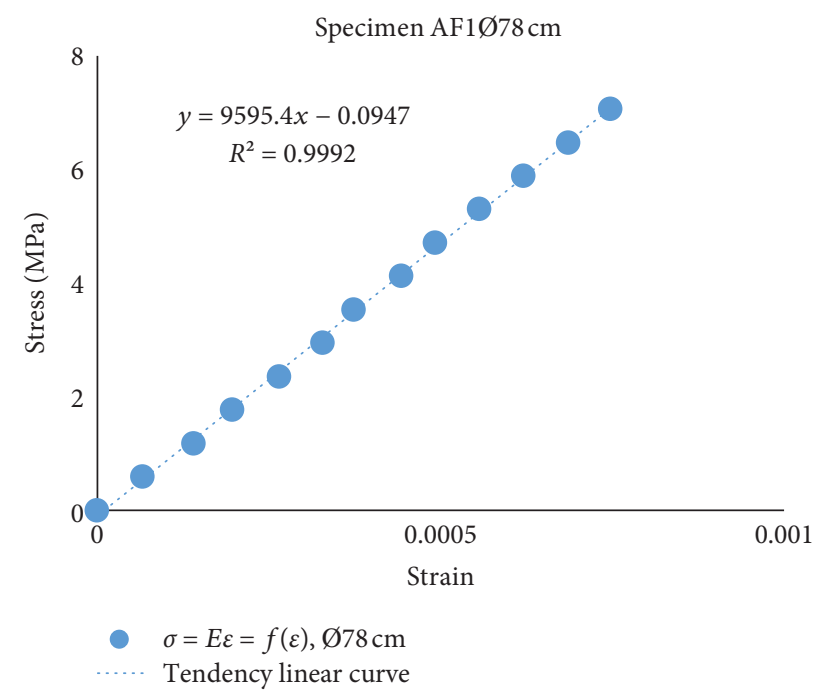

(c)

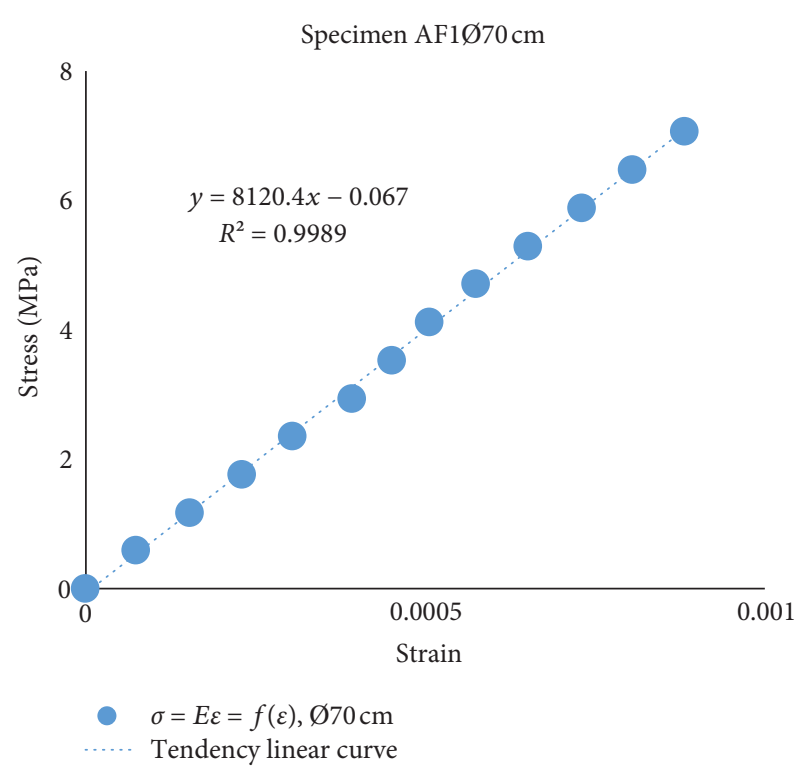

(b)

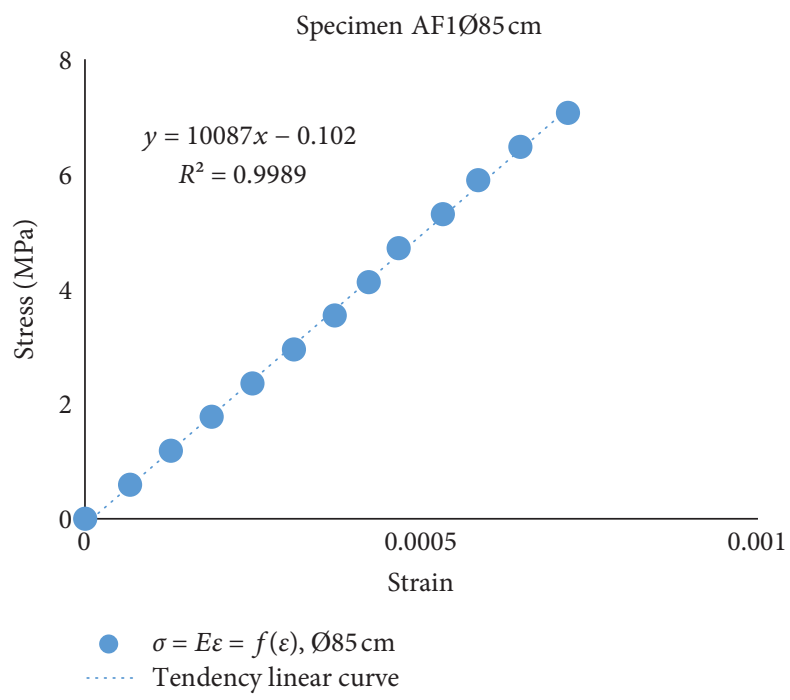

(d)

Figure 10: (a, b, c, and d): Samples of linear regression curves used to calculate the MOE. 


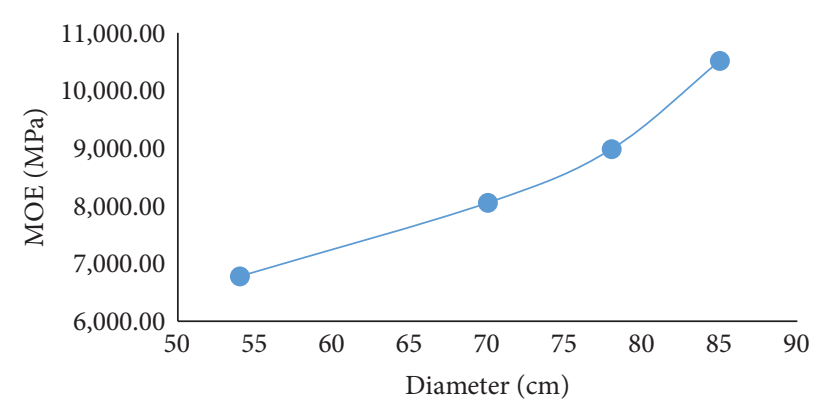

Figure 11: Variation curve of the 4-point bending modulus of elasticity as a function of diameter.

TABLE 4: Failure stresses in axial compression, diameter $54 \mathrm{~cm}$ and $70 \mathrm{~cm}$.

\begin{tabular}{|c|c|c|c|c|c|c|}
\hline \multirow{2}{*}{ Specimen } & \multicolumn{3}{|c|}{$\operatorname{ACL}(\varnothing 54)$} & \multicolumn{3}{|c|}{$\operatorname{ACL}(\varnothing 70)$} \\
\hline & $\sigma_{u H}(\mathrm{MPa})$ & $\sigma_{u 12}(\mathrm{MPa})$ & $H(\%)$ & $\sigma_{u H}(\mathrm{MPa})$ & $\sigma_{u 12}(\mathrm{MPa})$ & $H(\%)$ \\
\hline 1 & 68.42 & 68.11 & 11.89 & 68.42 & 66.40 & 11.26 \\
\hline 2 & 66.71 & 66.76 & 12.02 & 68.42 & 66.87 & 11.43 \\
\hline 3 & 68.42 & 68.38 & 11.99 & 71.84 & 70.30 & 11.46 \\
\hline 4 & 68.42 & 67.62 & 11.71 & 70.13 & 69.18 & 11.66 \\
\hline 5 & 66.71 & 65.96 & 11.72 & 68.42 & 66.63 & 11.35 \\
\hline 6 & 66.71 & 65.71 & 11.63 & 68.42 & 66.83 & 11.42 \\
\hline 7 & 66.71 & 66.17 & 11.80 & 70.13 & 68.47 & 11.41 \\
\hline 8 & 68.42 & 67.79 & 11.77 & 68.42 & 66.85 & 11.43 \\
\hline 9 & 66.71 & 66.05 & 11.75 & 68.42 & 66.41 & 11.27 \\
\hline 10 & 66.71 & 64.99 & 11.36 & 66.71 & 65.16 & 11.42 \\
\hline 11 & 68.42 & 67.61 & 11.70 & 71.84 & 70.49 & 11.53 \\
\hline 12 & 68.42 & 66.60 & 11.34 & 71.84 & 69.54 & 11.20 \\
\hline Average & 67.56 & 66.81 & 11.72 & 69.41 & 67.76 & 11.40 \\
\hline Standard deviation & 0.89 & 1.07 & 0.21 & 1.70 & 1.75 & 0.13 \\
\hline
\end{tabular}

TABLE 5: Failure stresses in axial compression, diameter $78 \mathrm{~cm}$ and $85 \mathrm{~cm}$.

\begin{tabular}{|c|c|c|c|c|c|c|}
\hline \multirow{2}{*}{ Specimen } & \multicolumn{3}{|c|}{$\operatorname{ACL}(\varnothing 78)$} & \multicolumn{3}{|c|}{$\operatorname{ACL}(\varnothing 85)$} \\
\hline & $\sigma_{\mathrm{uH}}(\mathrm{MPa})$ & $\left.\sigma_{\mathrm{u} 12} \mathrm{MPa}\right)$ & $\mathrm{H}(\%)$ & $\sigma_{\mathrm{uH}}(\mathrm{MPa})$ & $\sigma_{\mathrm{u} 12}(\mathrm{MPa})$ & $\mathrm{H}(\%)$ \\
\hline 1 & 71.84 & 71.33 & 11.82 & 83.81 & 82.10 & 11.49 \\
\hline 2 & 71.84 & 71.53 & 11.89 & 88.94 & 86.67 & 11.36 \\
\hline 3 & 71.84 & 69.92 & 11.33 & 83.81 & 83.77 & 11.99 \\
\hline 4 & 71.84 & 69.27 & 11.10 & 88.94 & 84.61 & 10.78 \\
\hline 5 & 71.84 & 71.05 & 11.73 & 88.94 & 86.72 & 11.38 \\
\hline 6 & 71.84 & 69.80 & 11.29 & 76.97 & 77.11 & 12.05 \\
\hline 7 & 70.13 & 68.86 & 11.55 & 88.94 & 85.41 & 11.01 \\
\hline 8 & 70.13 & 69.38 & 11.73 & 78.68 & 78.55 & 11.96 \\
\hline 9 & 71.84 & 71.13 & 11.75 & 83.81 & 85.51 & 12.51 \\
\hline 10 & 70.13 & 68.96 & 11.58 & 76.97 & 77.51 & 12.18 \\
\hline 11 & 70.13 & 69.80 & 11.88 & 75.26 & 75.98 & 12.24 \\
\hline 12 & 71.84 & 70.84 & 11.65 & 76.97 & 76.16 & 11.74 \\
\hline Average & 71.27 & 70.15 & 11.61 & 82.67 & 81.67 & 11.72 \\
\hline Standard deviation & 0.84 & 0.97 & 0.25 & 5.47 & 4.30 & 0.52 \\
\hline
\end{tabular}

from the same log; there is a difference in the instantaneous elastic deformations for the same level of stress. This proves the complexity in the behavior of the wood material. This difference may be due to the extraction zone of the specimens on the log and the method of loading the specimen which is not yet automated in the laboratory.
3.4.2. Fractional Maxwell Model. We used the fractional Maxwell model to simulate the creep data of the AF11(Ø54) specimen subjected to a low stress of $16.1865 \mathrm{MPa}$, for a loading time of 10 hours (Figure 17).

On the strain speed curve (Figure 7 ), the time $t_{1}$ corresponds to the instant at which the deformation speed becomes constant. For the specimen under consideration, $t_{1}=55 \mathrm{~min}$. 


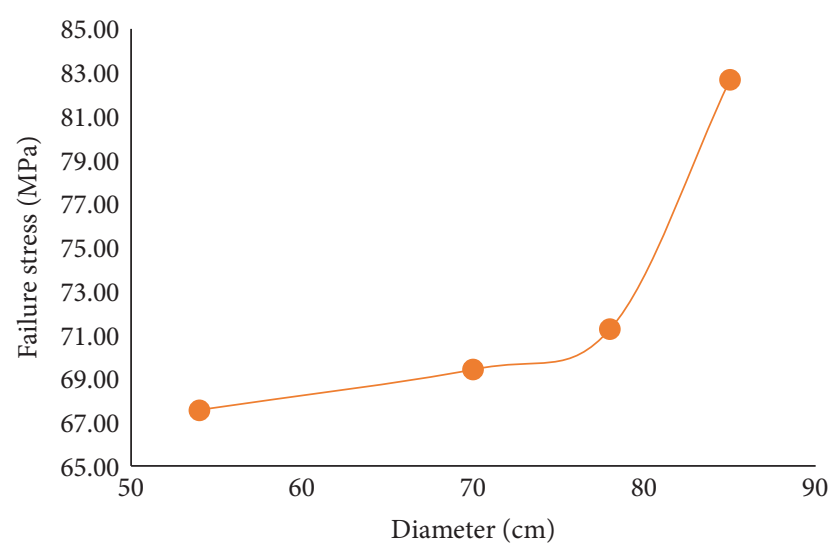

FIgURE 12: Curve of mean compressive failure stresses as a function of diameter in axial direction.

TABLE 6: Failure stresses in radial compression, diameter $54 \mathrm{~cm}$ and $70 \mathrm{~cm}$.

\begin{tabular}{|c|c|c|c|c|c|c|}
\hline \multirow{2}{*}{ Specimen } & \multicolumn{3}{|c|}{$\operatorname{ACR}(\varnothing 54)$} & \multicolumn{3}{|c|}{$\operatorname{ACR}(\varnothing 70)$} \\
\hline & $\sigma_{u H}(\mathrm{MPa})$ & $\sigma_{u 12}(\mathrm{MPa})$ & $H(\%)$ & $\sigma_{u H}(\mathrm{MPa})$ & $\sigma_{u 12}(\mathrm{MPa})$ & $H(\%)$ \\
\hline 1 & 23.09 & 23.61 & 12.56 & 23.52 & 24.04 & 12.55 \\
\hline 2 & 21.38 & 21.89 & 12.59 & 24.37 & 24.99 & 12.63 \\
\hline 3 & 23.09 & 24.06 & 13.05 & 23.26 & 23.56 & 12.32 \\
\hline 4 & 23.09 & 22.89 & 11.79 & 23.69 & 24.10 & 12.44 \\
\hline 5 & 23.09 & 23.54 & 12.48 & 24.80 & 25.59 & 12.79 \\
\hline 6 & 23.09 & 23.41 & 12.35 & 24.54 & 25.19 & 12.65 \\
\hline 7 & 22.24 & 22.96 & 12.82 & 24.80 & 24.47 & 11.67 \\
\hline 8 & 23.09 & 23.28 & 12.21 & 24.80 & 25.43 & 12.63 \\
\hline 9 & 22.24 & 22.79 & 12.62 & 24.72 & 25.28 & 12.57 \\
\hline 10 & 22.24 & 22.60 & 12.40 & 23.95 & 23.70 & 11.75 \\
\hline 11 & 23.52 & 24.36 & 12.89 & 24.80 & 24.47 & 11.67 \\
\hline 12 & 23.09 & 23.67 & 12.63 & 24.80 & 25.11 & 12.31 \\
\hline Average & 22.77 & 23.25 & 12.53 & 24.34 & 24.66 & 12.33 \\
\hline Standard deviation & 0.61 & 0.67 & 0.33 & 0.58 & 0.69 & 0.41 \\
\hline
\end{tabular}

TABLE 7: Failure stresses in radial compression, diameter $78 \mathrm{~cm}$ and $85 \mathrm{~cm}$.

\begin{tabular}{|c|c|c|c|c|c|c|}
\hline \multirow{2}{*}{ Specimen } & \multicolumn{3}{|c|}{$\operatorname{ACR}(\varnothing 78)$} & \multicolumn{3}{|c|}{$\operatorname{ACR}(\varnothing 85)$} \\
\hline & $\sigma_{u H}(\mathrm{MPa})$ & $\sigma_{u 12}(\mathrm{MPa})$ & $H(\%)$ & $\sigma_{u H}(\mathrm{MPa})$ & $\sigma_{u 12}(\mathrm{MPa})$ & $H(\%)$ \\
\hline 1 & 27.16 & 26.82 & 11.69 & 31.64 & 32.41 & 12.60 \\
\hline 2 & 27.20 & 27.24 & 12.04 & 28.22 & 28.96 & 12.66 \\
\hline 3 & 26.43 & 26.42 & 12.00 & 29.93 & 30.78 & 12.70 \\
\hline 4 & 26.77 & 27.48 & 12.67 & 31.81 & 32.46 & 12.51 \\
\hline 5 & 26.34 & 26.74 & 12.38 & 29.93 & 32.52 & 14.16 \\
\hline 6 & 27.02 & 26.79 & 11.78 & 28.51 & 29.26 & 12.65 \\
\hline 7 & 25.74 & 26.44 & 12.68 & 31.64 & 32.30 & 12.52 \\
\hline 8 & 26.25 & 26.71 & 12.44 & 28.74 & 28.74 & 12.01 \\
\hline 9 & 25.91 & 26.33 & 12.40 & 29.08 & 29.44 & 12.31 \\
\hline 10 & 27.02 & 26.82 & 11.81 & 28.65 & 29.23 & 12.51 \\
\hline 11 & 26.94 & 26.77 & 11.84 & 28.82 & 29.67 & 12.74 \\
\hline 12 & 27.20 & 27.91 & 12.66 & 29.93 & 30.74 & 12.68 \\
\hline Average & 26.67 & 26.87 & 12.20 & 29.74 & 30.54 & 12.67 \\
\hline Standard deviation & 0.51 & 0.46 & 0.38 & 1.31 & 1.52 & 0.51 \\
\hline
\end{tabular}




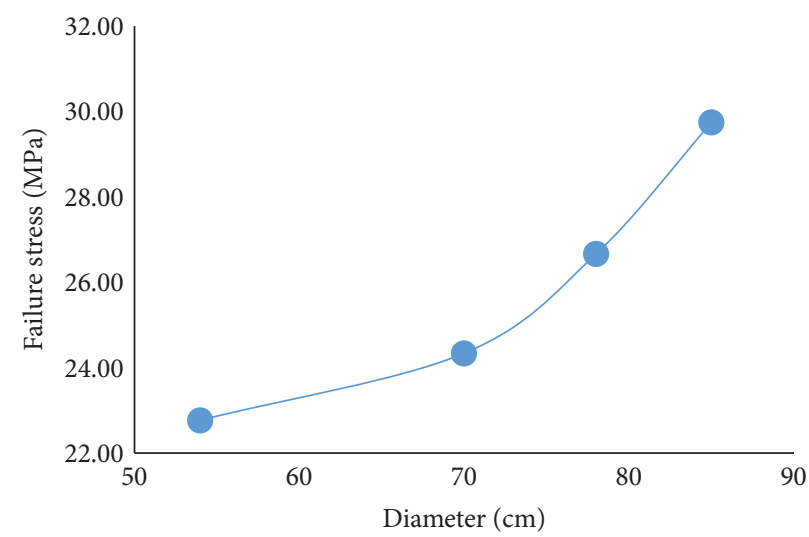

FIgURE 13: The curve of mean compressive failure stresses as a function of diameter in radial direction.

TABLE 8: Tangential compressive failure stresses, diameters $54 \mathrm{~cm}$ and $70 \mathrm{~cm}$.

\begin{tabular}{|c|c|c|c|c|c|c|}
\hline \multirow{2}{*}{ Specimen } & \multicolumn{3}{|c|}{$\operatorname{ACT}(\varnothing 54)$} & \multicolumn{3}{|c|}{$\operatorname{ACT}(\varnothing 70)$} \\
\hline & $\sigma_{u H}(\mathrm{MPa})$ & $\sigma_{u 12}(\mathrm{MPa})$ & $H(\%)$ & $\sigma_{u H}(\mathrm{MPa})$ & $\sigma_{u 12}(\mathrm{MPa})$ & $H(\%)$ \\
\hline 1 & 18.81 & 19.95 & 13.51 & 22.24 & 24.08 & 14.07 \\
\hline 2 & 20.10 & 21.50 & 13.74 & 20.53 & 21.69 & 13.42 \\
\hline 3 & 18.81 & 19.68 & 13.15 & 21.38 & 22.57 & 13.39 \\
\hline 4 & 18.81 & 19.99 & 13.56 & 20.53 & 21.49 & 13.18 \\
\hline 5 & 20.10 & 21.13 & 13.28 & 23.09 & 24.48 & 13.50 \\
\hline 6 & 17.45 & 18.39 & 13.36 & 20.10 & 21.15 & 13.31 \\
\hline 7 & 17.96 & 19.12 & 13.62 & 22.24 & 23.49 & 13.41 \\
\hline 8 & 17.10 & 18.14 & 13.51 & 21.38 & 22.55 & 13.37 \\
\hline 9 & 17.62 & 18.85 & 13.75 & 20.95 & 22.47 & 13.81 \\
\hline 10 & 17.96 & 18.93 & 13.36 & 20.10 & 21.42 & 13.65 \\
\hline 11 & 19.79 & 21.01 & 13.54 & 20.53 & 21.90 & 13.68 \\
\hline 12 & 17.10 & 17.92 & 13.20 & 20.53 & 21.65 & 13.37 \\
\hline Average & 18.47 & 19.55 & 13.47 & 21.13 & 22.41 & 13.51 \\
\hline Standard deviation & 1.10 & 1.20 & 0.20 & 0.96 & 1.09 & 0.25 \\
\hline
\end{tabular}

Table 9: Tangential compressive failure stresses, diameters $78 \mathrm{~cm}$ and $85 \mathrm{~cm}$.

\begin{tabular}{|c|c|c|c|c|c|c|}
\hline \multirow{2}{*}{ Specimen } & \multicolumn{3}{|c|}{$\operatorname{ACT}(\varnothing 78)$} & \multicolumn{3}{|c|}{ ACT(Ø85) } \\
\hline & $\sigma_{u H}(\mathrm{MPa})$ & $\sigma_{u 12}(\mathrm{MPa})$ & $H(\%)$ & $\sigma_{u H}(\mathrm{MPa})$ & $\sigma_{u 12}(\mathrm{MPa})$ & $H(\%)$ \\
\hline 1 & 23.52 & 24.94 & 13.51 & 29.93 & 30.88 & 12.80 \\
\hline 2 & 23.95 & 24.47 & 12.55 & 29.08 & 29.82 & 12.64 \\
\hline 3 & 23.95 & 25.22 & 13.33 & 28.22 & 29.01 & 12.70 \\
\hline 4 & 24.80 & 25.85 & 13.06 & 28.22 & 29.12 & 12.80 \\
\hline 5 & 23.95 & 25.44 & 13.56 & 26.51 & 28.36 & 13.74 \\
\hline 6 & 24.37 & 25.62 & 13.28 & 27.37 & 28.17 & 12.73 \\
\hline 7 & 23.52 & 24.79 & 13.36 & 25.66 & 26.13 & 12.46 \\
\hline 8 & 23.95 & 25.30 & 13.41 & 28.22 & 28.58 & 12.31 \\
\hline 9 & 24.37 & 25.63 & 13.29 & 25.66 & 26.24 & 12.57 \\
\hline 10 & 23.52 & 25.16 & 13.75 & 26.94 & 27.30 & 12.33 \\
\hline 11 & 22.24 & 23.44 & 13.36 & 28.22 & 28.79 & 12.51 \\
\hline 12 & 23.95 & 24.67 & 12.76 & 26.51 & 27.31 & 12.76 \\
\hline Average & 23.84 & 25.05 & 13.27 & 27.54 & 28.31 & 12.70 \\
\hline Standard deviation & 0.63 & 0.65 & 0.34 & 1.33 & 1.40 & 0.37 \\
\hline
\end{tabular}




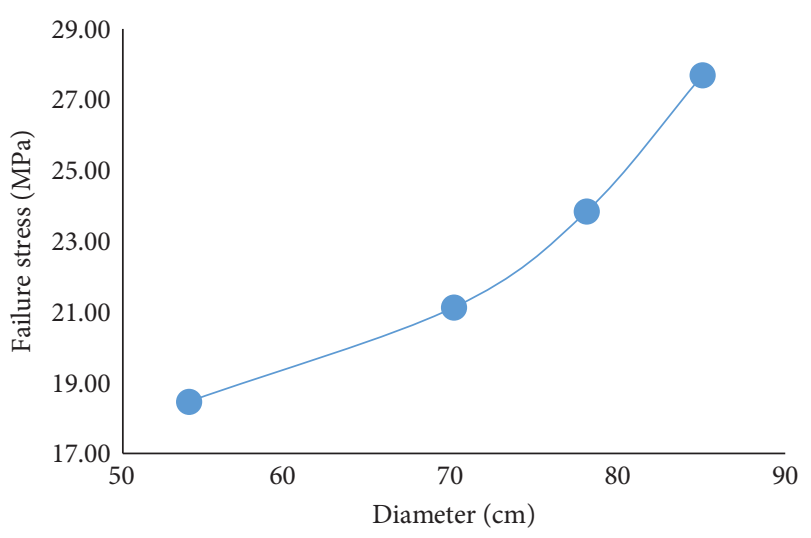

Figure 14: The curve of mean compressive failure stresses as a function of diameter in radial direction.

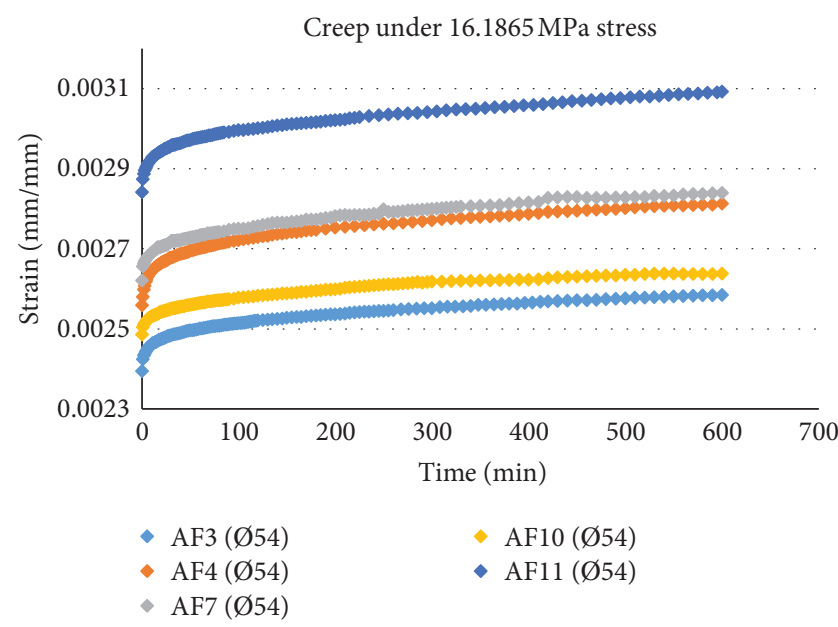

Figure 15: Network of 10-hour creep curves of $\varnothing 54$ specimens under a load of $16.1865 \mathrm{MPa}$.

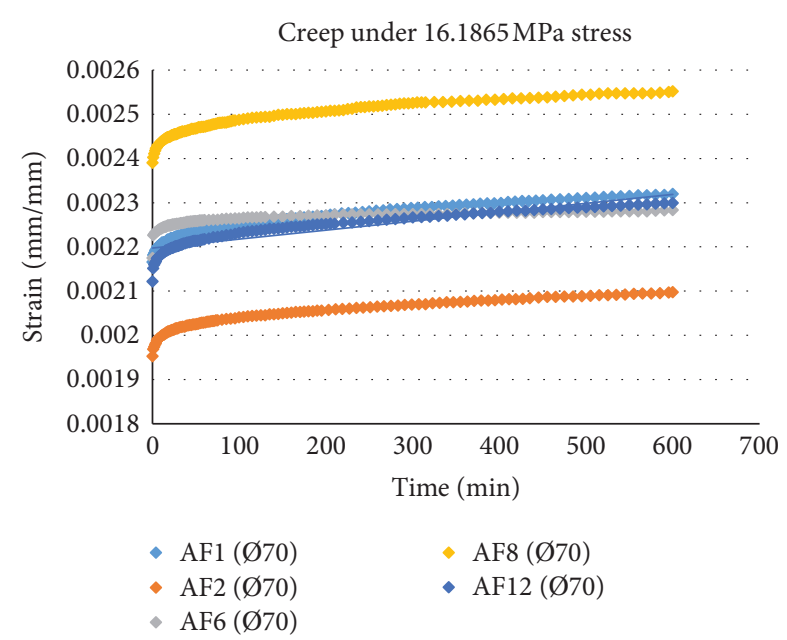

Figure 16: Network of 10-hour creep curves of $\varnothing 70$ specimens under a load of $16.1865 \mathrm{MPa}$.

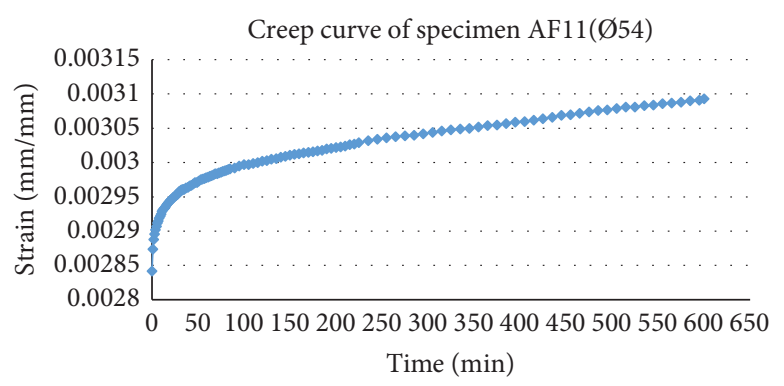

Figure 17: 10-hour creep curves of Ø54 specimens under a load of $16.1865 \mathrm{MPa}$.

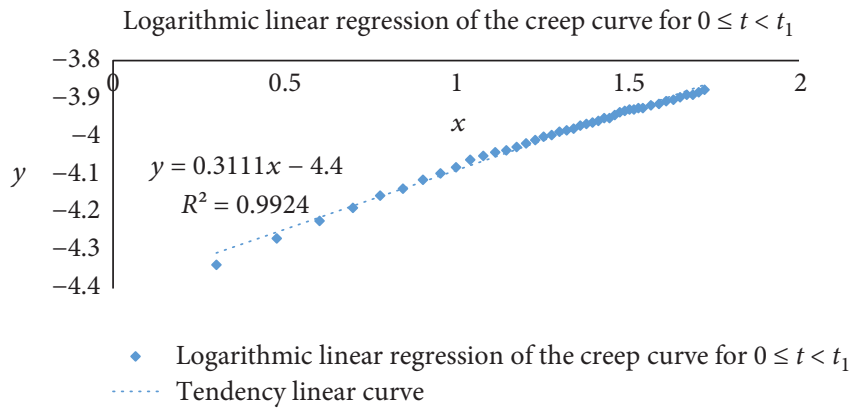

FIgURE 18: Logarithmic linear regression curve of creep in the interval $0 \leq t<t_{1}$.

TABLE 10: MF parameters for specimen creep AF11(Ø54) under $\sigma=16.1865 \mathrm{MPa}$.

\begin{tabular}{ccccc}
\hline \multirow{2}{*}{$E(\mathrm{MPa})$} & \multicolumn{2}{c}{ Interval $0 \leq t<t_{1}$} & \multicolumn{2}{c}{ Interval $t_{1} \leq t \leq t_{2}$} \\
& $n_{1}$ & $\eta^{n_{1}}\left(\mathrm{MPa} \cdot \mathrm{min}^{n_{1}}\right)$ & $n_{2}$ & $\eta^{n_{2}}\left(\mathrm{MPa} \cdot \min ^{n_{2}}\right)$ \\
\hline 5695.461 & 0.311 & $4.538 \times 10^{5}$ & 0.785 & $1.943 \times 10^{7}$ \\
\hline
\end{tabular}

It can be deduced from the linear regression in (Figure 18) and (19) that the values of the constants $n_{1}$ and $\eta^{n_{1}}$ can be easily determined.

From the linear regression in Figure 8 and (24), one can easily deduce the values of the constants $n_{2}$ and $\eta^{n_{2}}$.

Table 10 summarizes the MF parameters used to plot the creep prediction curve.

Figure 19 shows the theoretical (MF) creep curve according to the parameters in Table 10. As shown in this figure, the fractional order variable of the Maxwell constitutive model has good compatibility with the experimental data. The divergence observed from time $t=335 \mathrm{~min}$ between the experimental curve and the MF prediction curve reflects the nonlinearity in the behavior of the AF11(Ø54) specimen from this instant.

Table 11 summarizes the set of 10 -hour creep parameters per diameter of the MF model, under $\sigma=16.1865 \mathrm{MPa}$ of stress. Overall, we note that the MF model's MOE is an increasing function of the diameter 


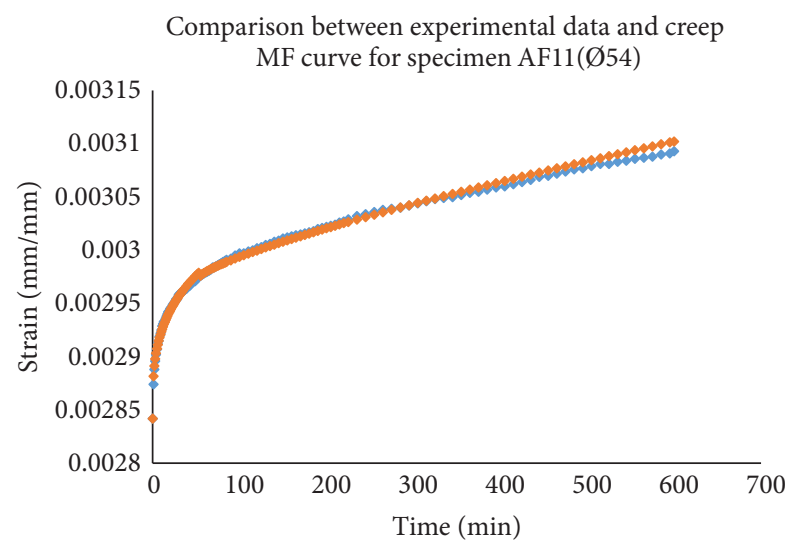

- Experimental curve of creep in the interval $0 \leq t \leq t_{2}$

FIgURE 19: Experimental and MF prediction creep curves of specimen AF11(Ø54).

TABLE 11: Summary of 10-hour MF creep parameters per diameter.

\begin{tabular}{|c|c|c|c|c|c|c|}
\hline \multirow{2}{*}{ Diameter $(\mathrm{cm})$} & \multirow{2}{*}{ Specimen } & \multirow{2}{*}{$E(\mathrm{MPa})$} & \multicolumn{2}{|c|}{ Interval $0 \leq t<t_{1}$} & \multicolumn{2}{|c|}{ Interval $t_{1} \leq t \leq t_{2}$} \\
\hline & & & $n_{1}$ & $\eta^{n_{1}}\left(\mathrm{MPa} \times \min ^{n_{1}}\right) \times 10^{5}$ & $n_{2}$ & $\eta^{n_{2}}\left(\mathrm{MPa} \times \min ^{n_{2}}\right) \times 10^{7}$ \\
\hline \multirow{5}{*}{$\mathrm{AF}(\varnothing 54)$} & 3 & 6758.455 & 0.293 & 5.463 & 0.732 & 1.792 \\
\hline & 4 & 6325.322 & 0.283 & 3.997 & 0.757 & 1.927 \\
\hline & 7 & 6175.696 & 0.293 & 5.112 & 0.743 & 1.467 \\
\hline & 10 & 6511.062 & 0.334 & 8.836 & 0.705 & 1.559 \\
\hline & 11 & 5695.461 & 0.311 & 4.538 & 0.785 & 1.943 \\
\hline \multirow{5}{*}{$\operatorname{AF}(\varnothing 70)$} & 1 & 7472.992 & 0.338 & 9.811 & 0.886 & 5.714 \\
\hline & 2 & 8288.018 & 0.293 & 7.710 & 0.811 & 4.164 \\
\hline & 6 & 7442.069 & 0.135 & 3.492 & 0.592 & 3.491 \\
\hline & 8 & 6769.762 & 0.310 & 7.786 & 0.745 & 2.245 \\
\hline & 12 & 7528.605 & 0.264 & 5.429 & 0.834 & 4.656 \\
\hline \multirow{3}{*}{$\mathrm{AF}(\varnothing 78)$} & 5 & 8903.465 & 0.318 & 9.363 & 0.651 & 2.207 \\
\hline & 17 & 7802.354 & 0.225 & 7.243 & 0.771 & 2.243 \\
\hline & 19 & 8712.340 & 0.327 & 8.205 & 0.642 & 3.408 \\
\hline \multirow{3}{*}{$\mathrm{AF}(\varnothing 85)$} & 13 & 9394.370 & 0.215 & 9.255 & 0.869 & 6.669 \\
\hline & 21 & 8784.541 & 0.301 & 8.354 & 0.757 & 5.437 \\
\hline & 22 & 9496.481 & 0.241 & 7.865 & 0.845 & 5.417 \\
\hline
\end{tabular}

of Pericopsis elata. The other parameters, however, do not obey this behavioral logic.

\section{Conclusion}

This work was focused on the "variation of the mechanical properties of Pericopsis elata with respect to the age (diameter)." The general objective of this work was to study the mechanical characteristics of Pericopsis elata wood at different stages of growth in production forests. The results of the mechanical properties of this wood as a function of diameter (age), which to date had not yet been the subject of a specific study, proved to be very edifying and followed the same evolution logic as the physical properties [6]. Indeed, in both 4-point bending and compression tests, the results of failure stresses and moduli of elasticity revealed that these could lead decision-makers to revise the Minimum Operating Diameter downwards. An overall analysis of these results in the three orthotropic directions reveals that the orders of magnitude of the ultimate stresses and modulus of elasticity corroborate with those established in the literature, proving that the tests went well. Being a biomaterial, this wood presents a variability of mechanical properties, reason for which we opted for MF. The modelling of creep by the MF rheological model is in agreement with the experimental data; this is for stresses less than or equal to $\sigma_{0}=10.5 \mathrm{MPa}$. In general, we noticed an increasing evolution of these different properties with the diameter of the logs. From the $78 \mathrm{~cm}$ diameter, the studied properties increase strongly with the diameter (age). This allows us to confirm that this species can be exploited for diameters close to $80 \mathrm{~cm}$ or for trees approximately 200 years old [6]. Given the importance and scope of our study, there could be a problem of overexploitation of Pericopsis elata. To limit this new problem, we recommend that logging companies ensure the perennity of this species 
by strictly adhering to Cameroon's forestry code, which recommends that they replant woody species with high commercial value.

\section{Data Availability}

Data used to support the findings of this study are included within the article.

\section{Conflicts of Interest}

The authors declare that they have no conflicts of interest.

\section{Acknowledgments}

The authors thank the NGO ANAFOR for the facilities given during the collection of samples in the forest.

\section{References}

[1] F. B. Boyemba, Écologie de Pericopsis elata (Harms) Van Meeuwen (Fabaceae), arbre de forêt tropicale africaine à répartition agrégée, Ph.D. thesis, p. 181, Université Libre de Bruxelles, Bruxelles, Belgium, 2011.

[2] International Union for Conservation of Nature, IUCN Red List Categories and Criteria, IUCN, Gland, Switzerland, Second edition, 2012.

[3] N. Bourland, Y. L Kouadio, G. Colinet, and J. L. Doucet, "Pericopsis elata (Harms) Meeuwen in the southeastern part of Cameroon: ecological and pedological approaches to improve the management of an endangered commercial timber species," International Forestry Review, vol. 12, no. 5, p. 111, 2009.

[4] Pallisco, Fiche essence Assamela. In P-CE-E-04. Version 01, p. 66, Pallisco, Paris, France, 2007.

[5] Tropix7-Cirad, Fiches Techniques Essences Tropicales (Assamela, Teck, etc.), 2011.

[6] C. M. Fouotsa Woutsop, E. Foadieng, B. E. Mtopi Fotso, U. G. Azeufack Tonfack, P. K. Talla, and M. Fogue, "Contribution to the study of variations of physical properties of Pericopsis elata with respect to different stages of growth," American Journal of Materials Research, vol. 6, no. 2, pp. 11-20, 2019.

[7] Forest Products Laboratory, Wood Handbook-Wood as an Engineering Material, General Technical Report FPL-GTR190, p. 508, U.S. Department of Agriculture, Forest Service, Forest Products Laboratory, Madison, WI, USA, 2010.

[8] AFNOR, French STANDARD, NF B 51-008. Wood-Static Bending-Determination of Ultimate Strength in Static Bending Using Small Clear Specimens, p. 5, AFNOR, Paris, France, 1987.

[9] AFNOR, French STANDARD, NF B 51-016. Wood-Static Bending-Determination of Modulus of Elasticity in Static Bending Using Small Clear Specimens, p. 6, AFNOR, Paris, France, 1987.

[10] ASTM International, Test Methods for Small Clear Specimens of Timber, ASTM, West Conshohocken, PA, USA, ASTM D143-94, 2000.

[11] C. M. Greenwood, T. M. Fujiwara, L. J. Boothroyd et al., "Linkage of tuberculosis to chromosome 2q35 loci, including NRAMP1, in a large aboriginal Canadian family," American Journal of Human Genetics, vol. 67, 2000.
[12] P. K. Talla, "Nonlinear creep behavior of Raphia vinifera L. Arecacea under flexural load," International Journal of Mechanics and Solids, vol. 5, no. 2, pp. 151-172, 2010.

[13] P. K. Talla, E. Foadieng, C. M. Fouotsa Woutsop et al., "A contribution to the study of entandrophragma cylindricum sprague and lovoa trichilioïdes harms long term behavior," Revue Scientifque et Technique Forêt et Environnement du Bassin du Congo, vol. 5, pp. 10-21, 2015.

[14] AFNOR, British Standard, BS EN 408:1995, Timber Structures-Structural Timber and Glued Laminated Timber-Determination of Some Physical and Mechanical Properties, AFNOR, Paris, France, 1995.

[15] G. W. S. Blair, "The role of psychophysics in rheology," Journal of Colloid Science, vol. 2, no. 1, pp. 21-32, 1947.

[16] H. W. Zhou, C. P. Wang, Z. Q. Duan, M. Zhang, and J. F. Liu, "Time-based fractional derivative approach to creep constitutive model of salt rock," Science China Physics, Mechanics and Astronomy, vol. 42, no. 3, pp. 310-318, 2012.

[17] J. Gérard, A. Edi Kouassi, C. Daigremont, P. Détienne, D. Fouquet, and M. Vernay, Synthèse sur les Caractéristiques Technologiques de Référence des Principaux Bois Commerciaux Africains, p. 185, Campus International de Baillarguet, Montpellier, France, 1998.

[18] Tropix7-CIRAD, Fiches Techniques Essences Tropicales (Assamela, Teck, etc.), 2011.

[19] D. Guitard, Mécanique du Matériau Bois et Composites, Cepadues-Editions, vol. 176, p. 238, Toulouse, France, 1987. 